Conclusions Loss of communication is a key trigger for requesting withdrawal of NIV. However many patients' wishes are not known before developing profound communication difficulties. Establishing the wishes and comfort of patients with communication difficulties is complex, time consuming and worrying for doctors who need high level skills.

\title{
P 027 WITHDRAWAL OF NIV AT THE PATIENT'S REQUEST IN MND: EXPLORATION OF THE ISSUES RELATED TO COMMUNICATION
}

Christina Faull, ${ }^{1}$ Kay Phelps, ${ }^{2}$ Emma Regen, ${ }^{2}$ David Oilver, ${ }^{3}$ Christopher Mcdermott, ${ }^{4}$ Cassy Rowe-Haynes'. 'LOROS Hospice care for Leicester, Leicestershire and Rutland, Leicester, UK; ${ }^{2}$ Department of Health Sciences, University of Leicester; ${ }^{3}$ Wisdom Hospice, Kent; ${ }^{4}$ Institute for Translational Neuroscience, University of Sheffield.

10.1136/bmjspcare-2014-000654.68

Background Little is known about the withdrawal of NIV at the request of a patient who has become dependent on it. The NICE guidance on the use of NIV in MND (2010) identifies the lack of clarity in how this process should be facilitated, suggesting interviewing the professionals involved in such events as a focus of research.

Aims To explore issues related to communication in decision making about the withdrawal of NIV.

Method A retrospective qualitative interview study of the experiences of 20 Doctors including specialists in palliative care, respiratory, neurology and family practice.

Results The loss of the ability to communicate was a trigger for many patients to request withdrawal of NIV. Other patients vacillated in making a decision or were more reticent about discussions on continuance and doctors narratives suggested increasing desperation to try and establish their wishes before communication was lost. In the context of profound difficulty in communication and high levels of fatigability for the patient this was often time extremely consuming.

Doctors required sophisticated communication strategies to ensure capacity was established and their impression of the patient's view was accurate and consistently expressed.

Family were often in the position both of identifying that patients wanted to request that NIV was withdrawn and providing the evidence for the doctor of the patients understanding of the consequences.

The loss of the ability of patients to communicate and move meant doctors needed to make judgments about the patients' level of distress and the efficacy of symptom management. 